\title{
Demographic profile, pattern, practice of energy drink and substance use among undergraduate students in BPKIHS
}

\author{
Ramayan Prasad Kushwaha', Namita Kumari Mandal', Bhawesh Koirala², \\ Gajendra Prasad Rauniar ${ }^{3}$ \\ ${ }^{1}$ Assistant Professor, ${ }^{2}$ Associate Professor, ${ }^{3}$ Professor and Head, Department of Clinical Pharmacology and \\ Therapeutics, BP Koirala Institute of Health Sciences, Dharan, Nepal
}

\section{A B S T R A C T}

Background: The consumption of caffeinated energy drinks is a common practice among college students. Energy drinks are believed to increase energy, stamina, wakefulness, and reduce hangover symptoms. Aims and Objective: This study aims to find out the profile, pattern, practice of energy drink and substance use among undergraduate students in BP Koirala Institute of Health Sciences. Materials and Methods: It was a selfreported questionnaire based descriptive cross-sectional study. The questionnaire included demographic details, patterns of energy drink used, mixing practice of alcohol with energy drinks or other beverages, substance use behavior, and the knowledge about the main constituents of energy drinks. Alcohol mixing practice was further categorized into a) Alcohol + Energy drink mixing group, b) Alcohol + Other beverages mixing group, c) Only Alcohol group. Results: Out of 319 students, 188 (58.9\%) were male. The prevalence of energy drink use was 186 (58.3\%). Red Bull (176, 94.6\%) was the most preferred energy drink. The use of alcohol $(29,87.9 \%)$, tobacco $(20,60.6 \%)$, and marijuana $(13,39.4 \%)$ was more prevalent in students using energy drinks on a daily basis. Thirty percent (57) alcohol user students were mixed alcohol with energy drink among them $42(73.7 \%)$ used tobacco and $24(42.1 \%)$ used marijuana. Conclusion: The overall energy drinks use among the students was high. The occurrence of various substance misuse was more among those students who consumed energy drink more frequently or consumed it with alcohol. Frequent consumption of energy drinks alone or mix with alcohol is not recommended.

Key words: Alcohol; Diazepam; Energy drink; Tobacco; Marijuana
Access this article online

\section{Website:}

http://nepjol.info/index.php/AJMS DOI: 10.3126/ajms.v10i6.25860 E-ISSN: 2091-0576 P-ISSN: 2467-9100

\section{INTRODUCTION}

Energy drinks constituted high amounts of caffeine containing non-alcoholic beverage, such as Red Bull, Explosion, Hot6, Monster, etc. ${ }^{1,2}$ These caffeinated energy drinks are believed to increase energy, stamina, wakefulness and reduces hangover symptoms. The use of energy drinks alone or mixed with alcohol has been emerging as a high-risk drinking behavior and other substance use liability. ${ }^{2,3}$ Recent studies also suggest that the consumption of energy drinks is associated with higher marijuana, tobacco and other illicit drug use. ${ }^{3,4}$
In our country, the popularity of the combined use of caffeine and alcohol is growing on. Mixing of energy drinks and alcohol is a common practice among youngsters. Several studies done worldwide have linked many health hazards and increased risk-taking behavior like substance misuse after the frequent use of energy drink alone or combination with alcohol. ${ }^{2,5}$ Although, Food and Drug Administration (FDA) has banned the use of caffeine as a food additive for alcoholic beverages since $2010 .^{6}$ Till date, no study has been conducted in Nepal to observe the pattern and practice of energy drinks and other substance used among undergraduate medical students. 
Thus, this study aims to investigate the demographic profile of students, patterns of energy drinks used, mixing practice of alcohol with energy drinks or other beverages, substance use behavior, and the knowledge about the main constituents of energy drinks among the undergraduate students.

\section{MATERIALS AND METHODS}

It was a self-reported questionnaire based descriptive cross sectional study conducted among MBBS (Bachelor of Medicine, Bachelor of Surgery) and BDS (Bachelor of Dental Surgery) students at BP Koirala Institute of Health Science (BPKIHS), Dharan, Nepal. Ethical approval was obtained from the Institute Review Committee (IRC). Before initiation of the study, students were informed about the objectives of the study and written informed consent was taken. Inclusion criteria constituted all the students from both MBBS and BDS disciplines. Those students who did not agree to participate in the study or did not give informed consent were excluded from the study. Confidentiality and anonymity of the participants were maintained.

The sample size was calculated by using the following formula,

$$
\mathrm{n}=\mathrm{Z}^{2} \times \mathrm{P}(1-\mathrm{P}) / \mathrm{d}^{2}
$$

where,

$\mathrm{n}=$ sample size

$\mathrm{p}=$ prevalence of energy drink used in Nepal, $52 \%{ }^{1}$

$\mathrm{d}=$ margin of error, $5 \%$

$\mathrm{Z}=1.96$ at $95 \%$ Confidence Interval $\mathrm{n}=383.54 \approx 384$. By using the formula for finite population correction, $\mathrm{s}=$ $\mathrm{n} /(1+\mathrm{n} / \mathrm{N})$, the sample size for source population of 853 students was $384 /(1+384 / 853)=264.83 \approx 265$. However, the study was carried out on 319 students. Stratify sampling technique was used to select the sample. Self-prepared semistructured questionnaire was used for data collection, which was finalized after pre-testing on 30 students from different disciplines.These 30 students were later excluded from the study.

The survey was conducted using a self-prepared semi-structured questionnaire. The questionnaire mainly focused on the demographic details, types, and frequency of energy drink use, mixing practice of alcohol with energy drinks or other beverages, substance use behavior, and the knowledge about the main constituents of energy drinks. Students who had consumed at least one energy drink during the past 30 days was defined as an energy drink user. $^{5}$ The mixing practice was defined as the mixing of energy drink together with alcohol or consumed energy drink within 2 hours before or in between or 2 hours after the alcoholic drinks. ${ }^{7,8}$

Based on mixing practice, students were categorized into three categories: a) Energy drinks mixed with alcohol (Alcohol + Energy drink), b) Alcohol mixed with other non-alcoholic beverages (Alcohol + Other beverages), and c) Only alcohol used, not mixed with other beverages (Only Alcohol). All data were coded and entered into Microsoft Excel 2010 and analyzed with SPSS version 11.5 (SPSS Inc). A descriptive statistics such as frequency and percentage was calculated and apply.

\section{RESULTS}

Out of 319 students, males was $188(58.9 \%)$ and female was $131(41.1 \%)$. The age of the participants ranged from $17-28$ years with a mean age of $21.76 \pm 1.81$. The prevalence of energy drink use was 186 (58.3\%). About two-third (141, $65 \%)$ MBBS and 45 (44.1\%) BDS students drank energy drinks. The consumption of energy drinks was more in males $(141,75 \%)$ as compared to females $(45,34.4 \%)$. Its prevalence among the age group of 20 to 25 years was $169(60.2 \%)$ (Table 1).

The most common type of energy drink preferred by the students was Red Bull (176, 94.6\%) followed by Explosion $(47,25.3 \%)$. Half of the energy drink user students $(92,49.5 \%)$ were consumed energy drinks 1-4 times per week (Figure 1).

On comparing total substance use among energy drink user and non-user students, it was seen more in energy drink user $(69.4 \%$ vs $50.4 \%)$ students. The use of alcohol, tobacco, and marijuana was more among energy drink user students (Figure 2).

Study results showed that the frequency of consumption of energy drinks also affected the use of substances. The students who consumed energy drinks more frequently (daily or 5-7 times per week) had also more consumption of alcohol $(29,87.9 \%)$, tobacco $(20,60.6 \%)$, and marijuana $(13,39.4 \%)$ as compared to others (Figure 3 ).

Similarly, 57 students were mixed alcohol with energy drinks; among them 42 (73.3\%) used tobacco and 24 (42.1\%) used marijuana. The overall use of other substances was more in alcohol mixed with energy drinks group (Figure 4).

Knowledge regarding the presence of caffeine as the main constituent of energy drink in the total energy drink user (186) students was $62.9 \%$ (117), whereas 37.1\% (69) students did not know the constituent of energy drinks even though they consumed it. 


\begin{tabular}{|c|c|c|c|}
\hline Characteristics & $\begin{array}{l}\text { Energy drink users }(n=186) \\
n(\%)\end{array}$ & $\begin{array}{l}\text { Non-Energy drink users } \\
(n=133), n(\%)\end{array}$ & $\begin{array}{c}\text { Total students }(n=319) \\
n(\%)\end{array}$ \\
\hline \multicolumn{4}{|l|}{ Discipline } \\
\hline MBBS & $141(65)$ & $76(35)$ & $217(68)$ \\
\hline BDS & $45(44.1)$ & 57 (55.9) & $102(32)$ \\
\hline \multicolumn{4}{|l|}{ Study years } \\
\hline $1^{\text {st }}$ year & $27(46.6)$ & $31(53.4)$ & $58(18.2)$ \\
\hline $2^{\text {nd }}$ year & $33(60)$ & $22(40)$ & $55(17.2)$ \\
\hline $3^{\text {rd }}$ year & $34(54)$ & $29(46)$ & 63 (19.7) \\
\hline $4^{\text {th }}$ year & $45(57.7)$ & $33(42.3)$ & 78 (24.5) \\
\hline $5^{\text {th }}$ year & 47 (72.3) & $18(27.7)$ & $65(20.4)$ \\
\hline \multicolumn{4}{|l|}{ Age group (years) } \\
\hline$<20$ & $12(37.5)$ & $20(62.5)$ & $32(10.1)$ \\
\hline $20-25$ & $169(60.2)$ & $112(39.8)$ & $281(88.1)$ \\
\hline$>25$ & $5(83.3)$ & $1(16.7)$ & $6(1.8)$ \\
\hline \multicolumn{4}{|l|}{ Sex } \\
\hline Male & $141(75)$ & $47(25)$ & $188(58.9)$ \\
\hline Female & $45(34.4)$ & $86(65.6)$ & $131(41.1)$ \\
\hline \multicolumn{4}{|l|}{ Nationality } \\
\hline Nepali & $153(60.5)$ & $100(39.5)$ & $253(79.3)$ \\
\hline Indian & $33(50)$ & $33(50)$ & $66(20.7)$ \\
\hline \multicolumn{4}{|l|}{ Religion } \\
\hline Hindu & $147(57.6)$ & $128(42.4)$ & $302(94.7)$ \\
\hline Others & $12(70.6)$ & $5(29.4)$ & $17(5.3)$ \\
\hline \multicolumn{4}{|l|}{ Ethnicity } \\
\hline Brahman+Chhetri & $89(63.6)$ & $51(36.4)$ & $140(43.9)$ \\
\hline Newar+Dalit \& Janjati & $27(58.7)$ & $19(41.3)$ & $46(14.4)$ \\
\hline Madhesi+others & $70(52.6)$ & $63(47.4)$ & $133(41.7)$ \\
\hline
\end{tabular}

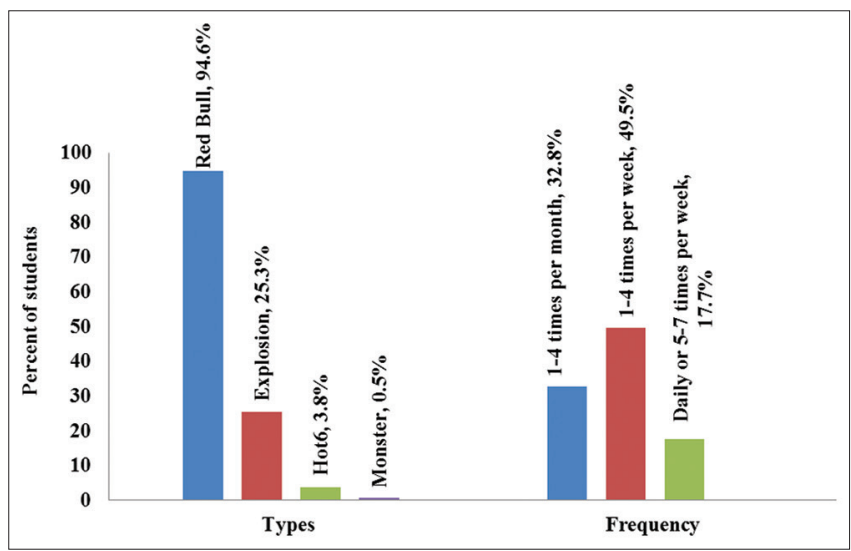

Figure 1: Pattern of energy drinks use among the students $(n=186)$.

\section{DISCUSSION}

Medical students are a vulnerable group of population to use energy drinks due to the requirement of constant alertness and mental functioning to combat the burden of academic and clinical activities. Energy drinks contain a high amount of stimulants such as caffeine, Guarana, taurine, etc. ${ }^{2}$ These stimulants may enhance the cross-sensitization between caffeine and other stimulant substances acting through the same neurological pathways. ${ }^{2}$ As a result, energy drink consumers may consume more energy drinks or alcohol and may indulge into the substance misuse. This survey was conducted to study the profile, pattern, practice of energy drink use among the undergraduate students in BPKIHS.

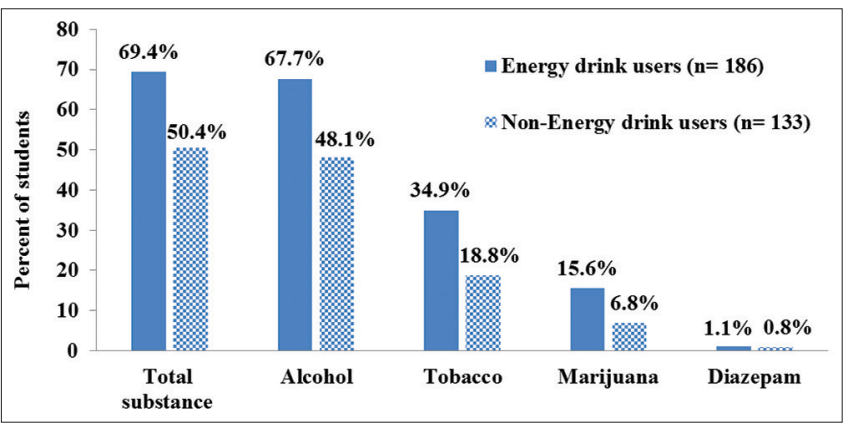

Figure 2: Substance use behavior among energy drink user and non-user students.

In our survey, the prevalence of energy drink consumption was $186(58.3 \%)$. A previous study showed that $52 \%$ out of 151 college students were used energy drinks in Nepal. ${ }^{1}$ Chang et al found that the prevalence of energy drink consumption among undergraduate students in Taiwan was $24.8 \%$, among them $48 \%$ used alcohol and $22.7 \%$ used tobacco. ${ }^{5}$ Similarly, Friis et al reported that $15.8 \%$ of participants used energy drinks weekly basis, in which $26.5 \%$ used tobacco, and $44.9 \%$ drank alcohol (include both high risk and binge drink). ${ }^{9}$ However, this present study showed a more proportion of energy drink users was consumed alcohol (67.7\%), tobacco (34.9\%), and marijuana $(15.6 \%)$ as compared to Chang et al and Friis et al studies. ${ }^{5,9}$ Because the consumption of energy drinks and substances is influenced by socio-demographic factors, education level, peer pressure, independent 


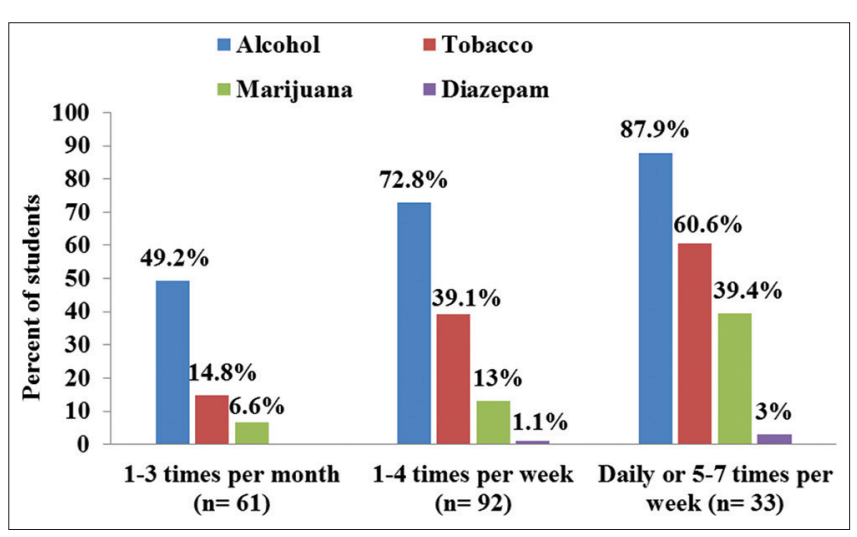

Figure 3: Stratification of substance used based on the frequency of energy drink use.

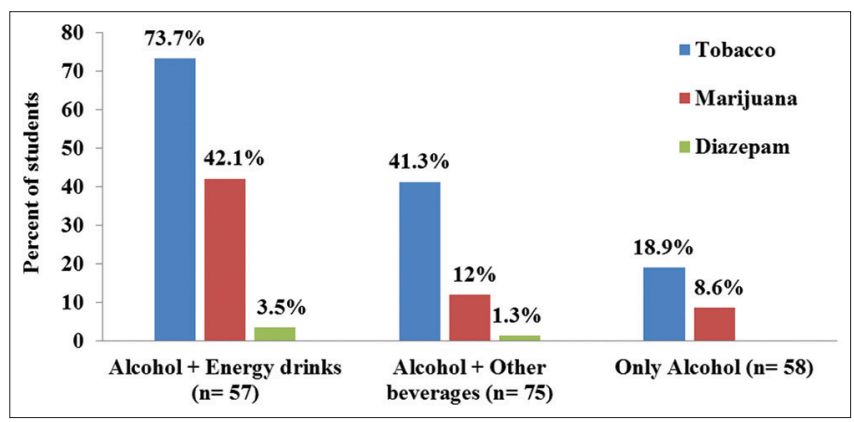

Figure 4: Alcohol mixing practice and other substance used behavior.

lifestyle, stressful activities, psychological factors and many more. ${ }^{2,5,10}$

It is interesting to find that, a greater proportion of frequent energy drink users (daily or 1-4 times per week) were used more substances. Among daily user of energy drinks, $87.9 \%$ used alcohol, $60.6 \%$ used tobacco, and $39.4 \%$ used marijuana. A study by Polak et al reported that $30.5 \%$ of students used energy drink $1-5$ times per month; among them $34 \%$ used tobacco, $55.9 \%$ drank alcohol, and $34.6 \%$ smoked marijuana. ${ }^{11}$ Similarly, $12.6 \%$ of students used energy drink more than six times per month; among them $52.1 \%$ used tobacco, $63 \%$ drank alcohol, and $48.4 \%$ smoked marijuana. ${ }^{11}$ The possible mechanism underlying the use of more substances among the frequent energy drink consumer is that caffeine is a rewarding stimulant, which primes the brain to the additional rewarding effects of the other stimulants. ${ }^{12}$ Neuropharmacologic mechanism shows that the use of caffeine reinforces the effects of nicotine and increase the use of nicotinic products. Therefore, tobacco users consume energy drinks and other caffeine-containing substances more frequently and in higher amounts as compared to the non-smokers. ${ }^{2}$

Furthermore, it was observed that the mixing practice of alcohol with energy drinks is more hazardous than the use of energy drink or alcohol alone. Consumption of alcohol mixed with energy drink might increase the liability for the consumption of tobacco, marijuana, and other substances. Our study showed that 30\% (57) of alcohol user students mixed energy drink with alcohol; among them $73.7 \%$ consumed tobacco and $42.1 \%$ consumed marijuana as compared to only alcohol users where tobacco and marijuana consumption was $18.9 \%$ and $8.6 \%$, respectively. Johnson et al surveyed in the United Kingdom and found that the consumers using alcohol mixed with energy drink were more likely to take illicit drugs $(24.9 \%)$ and to smoke $(25.8 \%)$ than consumers using only alcohol. ${ }^{7}$ It may be because caffeine present in energy drinks reduces an individual's perception of being drunk and other substance-related impairment. As a result, individuals may further indulge in various substance misuse. ${ }^{2}$

This study might help in education, prevention, screening, and policy making related to the risk of energy drink use. Although this study has several strengths, including the investigation of concomitant use of energy drink and other substances, some limitations should be noted. This study is a cross-sectional design, which cannot prove causality between an energy drink and substance use. The data of this study were based on the past 30-day's memory, self-reported and drug-related, which may produce recall and response biases. The sample was only medical students, so the finding of this study cannot be generalized to all Nepalese populations. A further study needs to be done to explore the frequency, amount, reasons and factors that influence the use of energy drink and substances.

\section{CONCLUSION}

The overall energy drink use among undergraduate students was high. The occurrence of various substances misuse was more among students who consumed energy drink more frequently or consumed it with alcohol. Frequent consumption of energy drinks alone or mixing with alcohol is not recommended. Preventive measures such as proper counseling and awareness programs about the potential risk of energy drinks and substances are further recommended for the betterment of the students.

\section{Questionnaire availability}

The questionnaire used for data collection of this study are available from the corresponding author upon request.

\section{ACKNOWLEDGEMENTS}

We would like to thank Dr. Deependra Prasad Sarraf, Dr. Laxman Khanal, Dr. Dilli Sher Rai and all the students for their support, guidance and participation. 


\section{REFERENCES}

1. Rai K, Rai H, Dahal S, Chaudhary $S$ and Shrestha $S$. Determination of Caffeine and Taurine Contents in Energy Drinks by HPLC-UV. J Food Sci Techol Nepal 2016; 9:66-73.

2. Terry-McElrath YM, O'Malley PM and Johnston LD. Energy drinks, soft drinks, and substance use among United States secondary school students. J Addict Med 2014; 8(1):6-13.

3. Reid SD, Ramsarran J, Brathwaite R, Lyman S, Baker A, Cornish DC, et al. Energy drink usage among university students in a Caribbean country: Patterns of use and adverse effects. J Epidemiol Glob Health 2015; 5(2):103-116.

4. Miller KE. Energy drinks, race, and problem behaviors among college students.J Adolesc Health 2008; 43(5):490-497.

5. Chang YJ, Peng CY and Lan YC. Consumption of Energy Drinks among Undergraduate Students in Taiwan: Related Factors and Associations with Substance Use. Int J Environ Res Public Health 2017; 14(9):e954.

6. Martz ME, Patrick ME and Schulenberg JE. Alcohol mixed with energy drink use among u.s. 12th-grade students: prevalence, correlates, and associations with unsafe driving. J Adolesc Health 2015; 56(5):557-563.
7. Johnson SJ, Alford C, Stewart K and Verster JC. A UK student survey investigating the effects of consuming alcohol mixed with energy drinks on overall alcohol consumption and alcoholrelated negative consequences. Prev Med Rep 2016; 4:496-501.

8. de Haan L, de Haan HA, Olivier B and Verster JC. Alcohol mixed with energy drinks: methodology and design of the Utrecht Student Survey. Int J Gen Med 2012; 5:889-898.

9. Friis K, Lyng $\mathrm{Jl}$, Lasgaard $\mathrm{M}$ and Larsen FB. Energy drink consumption and the relation to socio-demographic factors and health behaviour among young adults in Denmark: A populationbased study. Eur J Public Health 2014; 24(5):840-844.

10. Khanal P, Ghimire R, Gautam B, Dhungana S, Parajuli P, Jaiswal A, et al. Substance Use among Medical Students in Kathmandu Valley. J Nepal Med Assoc 2010; 49(180):267-272.

11. Polak K, Dillon P, Koch JR, Miller WG Jr, Thacker L and Svikis D. Energy drink use is associated with alcohol and substance use in eighth, tenth, and twelfth graders. Prev Med Rep 2016; 4:381-384

12. Emond JA, Gilbert-Diamond D, Tanski SE and Sargent JD. Energy drink consumption and the risk of alcohol use disorder among a national sample of adolescents and young adults. J Pediatr 2014; 165(6):1194-1200.

Authors Contribution:

RPK- Concept and Design of the study, Literature search, Review of literature, Data collection, Statistically analyzed and interpreted data, Prepared first draft of manuscript, Critical review of manuscript and review of the study; NKM- Concept and Design, Literature search, Review of literature, Data collection, Helped in preparing first draft of manuscript, Critical revision of manuscript; BK- Concept and Design, Review of literature, Critical revision of manuscript, Helped in preparing first draft of manuscript; GPR- Concept and Design, Critical revision of manuscript, helped and approved in preparing the manuscript to be published.

\section{Work attributed to:}

Department of Clinical Pharmacology and Therapeutics, BP Koirala Institute of Health Sciences, Dharan, Nepal.

Orcid ID:

Dr. Ramayan Prasad Kushwaha- (1) https://orcid.org/0000-0001-5004-8537

Dr. Namita Kumari Mandal- (1) https://orcid.org/0000-0002-1226-640X

Dr. Bhawesh Koirala- it https://orcid.org/0000-0001-8908-0913

Dr. Gajendra Prasad Rauniar- (1) https://orcid.org/0000-0002-7968-506X

Source of Support: Nil, Conflict of Interest: None. 